\title{
DESIGN AND ANALYSIS OF A MICRO CD- NOZZLE FOR GENERATING SUPERSONIC FLOW
}

\author{
Parameshwar Banakar \\ Department of Aeronautical Engg \\ KLS Gogte Institute of Technology \\ Belagavi, Karnataka, India
}

\author{
Venkatesh Kusnur \\ Department of Aeronautical Engg \\ KLS Gogte Institute of Technology \\ Belagavi, Karnataka, India
}

\author{
Mayur Anvekar \\ Department of Aeronautical Engg \\ KLS Gogte Institute of Technology \\ Belagavi, Karnataka, India
}

\begin{abstract}
This paper aims at design and analyses of a Convergent-Divergent nozzle in order to attain a supersonic flow at the exit of the nozzle which produces shock diamonds. Area ratios, diameters, and lengths for inlet, throat and exit are calculated mathematically with respect to a standard compressor and corresponding Mach numbers are calculated. Based on analytical results a Convergent -Divergent nozzle is designed in Catia V5 and the flow field analysis of CD nozzle is carried using Ansys fluent work bench. Both fluent results and analytical results are compared to quantify.
\end{abstract}

Keywords-Convergent-Divergent nozzle, supersonic flow, shock diamonds

\section{INTRODUCTION}

The nozzle is basically designed to increase the velocity of the fluid flow across it by converting heat and pressure into kinetic energy of fluid. In Aero-engines, it is used to produce efficient thrust. The fluid from subsonic velocity is accelerated to supersonic velocity using a Convergent- Divergent nozzle.

A Convergent-Divergent nozzle is a duct that is nipped in the middle, making a carefully balanced, asymmetric hourglass shape. It is used to accelerate a hot, pressurized gas passing through it to a higher supersonic speed in the axial (thrust) direction, by converting the heat energy of the flow into kinetic energy.

If the pressure $\&$ the mass flow rate through the nozzle are sufficient to reach the sonic speeds then choking occurs at the throat of a Convergent-Divergent nozzle and it produces supersonic flow downstream of throat. It means the entry pressure to the nozzle to be significantly more than the ambient at all the times. In addition, the pressure of the gas at the exit of the expansion portion of the exhaust of a nozzle must not be low. The exit pressure can be significantly below ambient pressure it exhausts into, but if it is too far below ambient, then the flow will cease to be supersonic. In practice, the nozzle exit pressure must be-around 2-3 times higher than the ambient pressure to attain supersonic flow.
The flow in the throat is sonic which means the Mach number is equal speed of sound. Downstream of the throat, the geometry diverges and the flow is isentropically expanded to a supersonic Mach number that depends on the nozzle area ratio.

If the flow is over expanded, at the nozzle exit shock diamonds are formed where as if the flow is under expanded then the expansion fans with shock diamonds will be formed.

\section{METHODOLOGY}

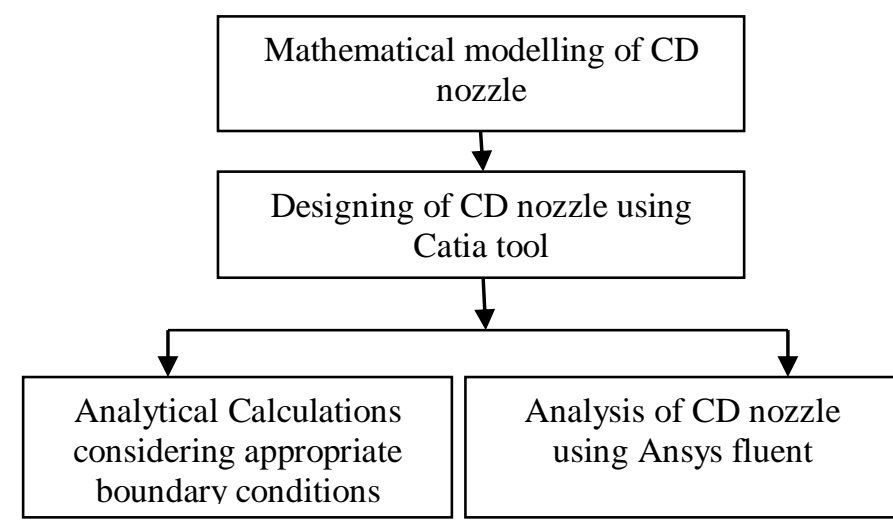

Fig.1 Methodology

Research starts with considering the capacity of a compressor of 8 bar and based on its pressure input design parameters are calculated for a Convergent-Divergent nozzle like nozzle dimensions and inlet mass flow rate, velocity and pressure. After that Convergent-Divergent nozzle is modelled using catia software.

The area relation for a given Mach number is given below:

\section{INPUT AND DESIGN PARAMETERS CALCULATIONS}


a) Effect of Compressors Mass Flow Rate on Design Parameters

Mass Flow Rate, $\dot{\mathrm{m}}=\frac{\mathrm{p}_{0} \dot{\mathrm{A}}}{\sqrt{\mathrm{T}_{0}}}(0.0414)$

Where, $\dot{\mathrm{m}}=$ mass flow rate in $\mathrm{Kg} / \mathrm{s}$

$\mathrm{Po}=$ Inlet Pressure in $\mathrm{Pa}$

T0 = Absolute Temperature in Kelvin

$\dot{\mathrm{A}}=$ Throat Area in $\mathrm{m} 2$

b) Specification of Compressor

\begin{tabular}{|c|c|}
\hline Model Number & TS 03 120 HN \\
\hline Piston displacement & $311 \mathrm{lpm}$ \\
\hline Free air delivery & $250 \mathrm{lpm}$ \\
\hline Motor power & $3 \mathrm{HP}, 2.2 \mathrm{~kW}$ \\
\hline Compressor rpm & $925 \mathrm{rpm}$ \\
\hline Number of cylinders & 2 \\
\hline Air receiver capacity & 160 litres \\
\hline Dimensions in $\mathbf{m m}$ & $1595 * 500 * 1000$ \\
\hline
\end{tabular}

Table.1 A two-stage reciprocating compressor specifications

c) Calculation for Throat Diameter

$0.00936=\frac{8 * 10^{5} \dot{A}}{\sqrt{300}}(0.0414)$

$\dot{\mathrm{A}}=3.915 * 10^{-6} \mathrm{~m} 2, \dot{\mathrm{A}}=$ Throat Area in $\mathrm{m} 2$ $\mathrm{D}=2.49 \mathrm{~mm}$

d) Calculation for Exit Diameter and Area Ratio

$\left(\frac{\mathrm{A}}{\dot{\mathrm{A}}}\right)=\left(\frac{\gamma+1}{2}\right)^{-\left(\frac{\gamma+1}{2(\gamma+1)}\right)}\left(\frac{2+(\gamma-1) \mathrm{M}^{2}}{2 \mathrm{M}}\right)^{\left(\frac{\gamma+1}{2(\gamma+1)}\right)}$

Where $\mathrm{A}=$ Exit area in $\mathrm{m} 2$

$\gamma=$ Specific heat ratio

$\mathrm{M}=$ Mach number

$\left(\frac{A}{3.915 * 10^{-6}}\right)=\left(\frac{1.4+1}{2}\right)^{-\left(\frac{1.4+1}{2(1.4+1)}\right)}\left(\frac{2+(1.4-1) 1.5^{2}}{2 * 1.5}\right)^{\left(\frac{1.4+1}{2(1.4+1)}\right)}$

$\mathrm{A}=7.23 * 10^{-6} \mathrm{~m}^{2} \mathrm{D}=3.041 \mathrm{~mm}$

e) Calculation of Nozzle Pressure Ratio (Npr)

$\frac{\mathrm{p}_{0}}{\mathrm{p}_{\mathrm{t}}}=\left(1+\frac{\gamma-1}{2}\left(\mathrm{M}_{\mathrm{t}}\right)^{2}\right)^{\frac{\gamma}{\gamma-1}}$

$\frac{p_{t}}{p_{o}}=0.2724$ f) Calculation of Temperature Ratio

$\frac{\mathrm{T}_{0}}{\mathrm{~T}}=\left[1+\frac{v-1}{2} \mathrm{~m}^{2}\right]$

$\frac{\mathrm{T}_{0}}{\mathrm{~T}}=1.45$

\section{MODELLING}

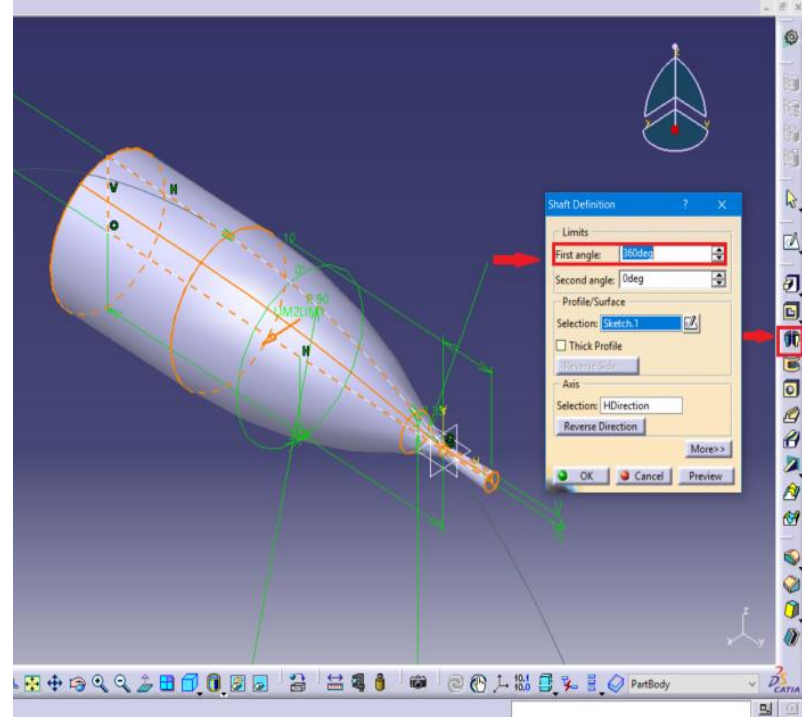

Fig. 2 Catia model of Convergent-Divergent Nozzle

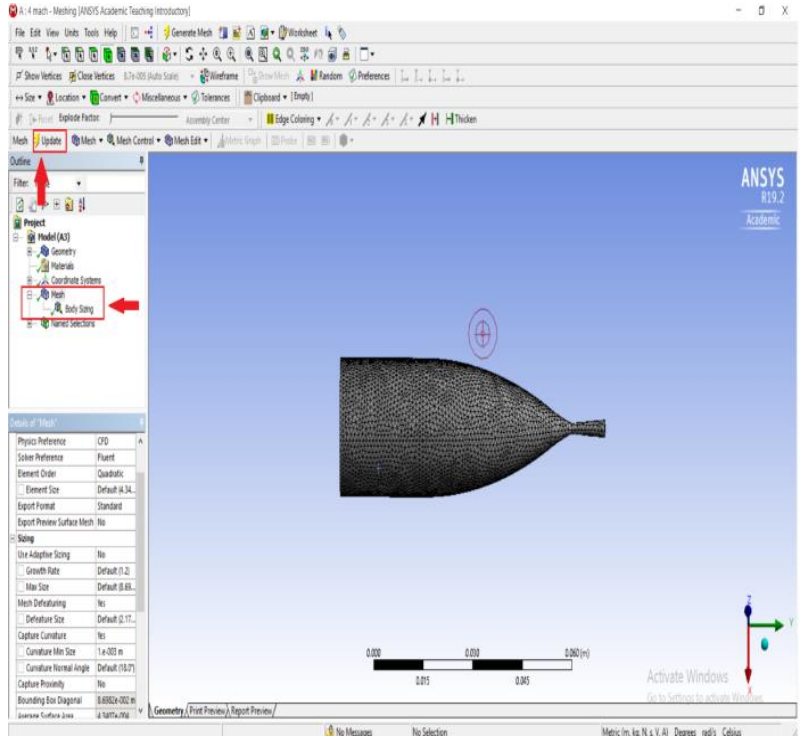

Fig. 3 Meshed Convergent-Divergent Nozzle

An unstructured mesh is generated with mesh size of $0.01 \mathrm{~mm}$ with effective grid independent studies.

V. RESULTS 
International Journal of Engineering Applied Sciences and Technology, 2020

Vol. 5, Issue 3, ISSN No. 2455-2143, Pages 427-430

Published Online July 2020 in IJEAST (http://www.ijeast.com)

\begin{tabular}{|c|c|c|}
\hline \multicolumn{3}{|c|}{ Analytical Results } \\
\hline Mach number & P/Po & Poutput in Pascal \\
& & \\
\hline 1.2 & $\mathbf{0 . 4 1 2}$ & $\mathbf{3 2 9 6 0 0}$ \\
\hline 1.5 & $\mathbf{0 . 2 7 2}$ & $\mathbf{2 1 7 6 0 0}$ \\
\hline 2 & $\mathbf{0 . 1 2 7}$ & $\mathbf{1 0 1 6 0 0}$ \\
\hline 2.2 & $\mathbf{0 . 0 9 3}$ & $\mathbf{7 4 4 0 0}$ \\
\hline 2.5 & $\mathbf{0 . 0 5 8}$ & $\mathbf{4 6 4 0 0}$ \\
\hline 2.7 & $\mathbf{0 . 0 4 2}$ & $\mathbf{3 3 6 0 0}$ \\
\hline 3.0 & $\mathbf{0 . 0 2 7}$ & $\mathbf{2 1 6 0 0}$ \\
\hline 3.2 & $\mathbf{0 . 0 2 0}$ & $\mathbf{1 6 0 0 0}$ \\
\hline 3.5 & $\mathbf{0 . 0 1 3}$ & $\mathbf{1 0 4 0 0}$ \\
\hline 4 & $\mathbf{0 . 0 0 6 5}$ & $\mathbf{4 8 0 0}$ \\
\hline
\end{tabular}

Table.2 Mach number with respect to pressure ratios

\section{CFD COUNTER PLOTS}

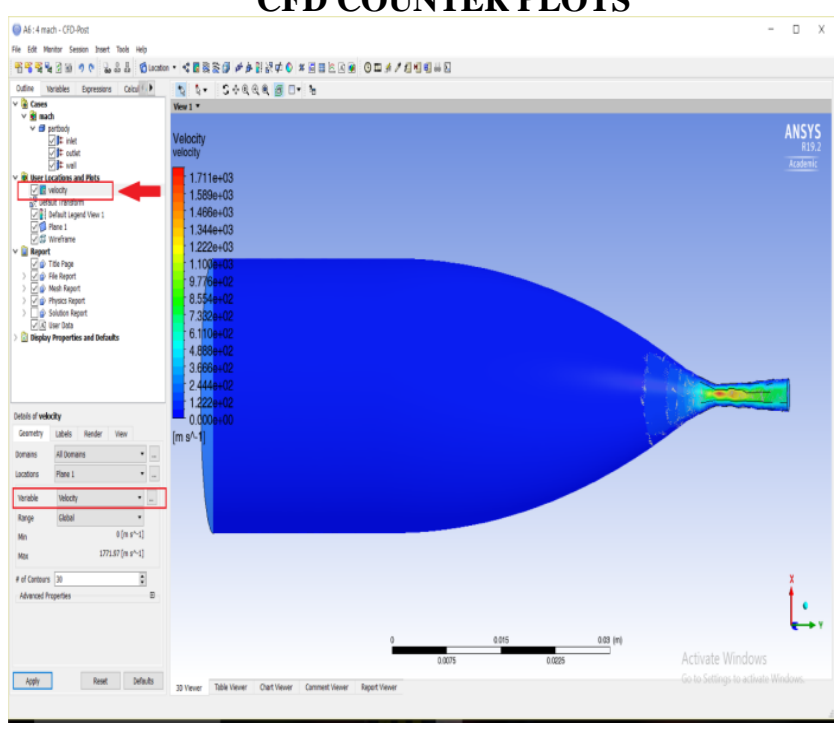

Fig. 4 Velocity contours

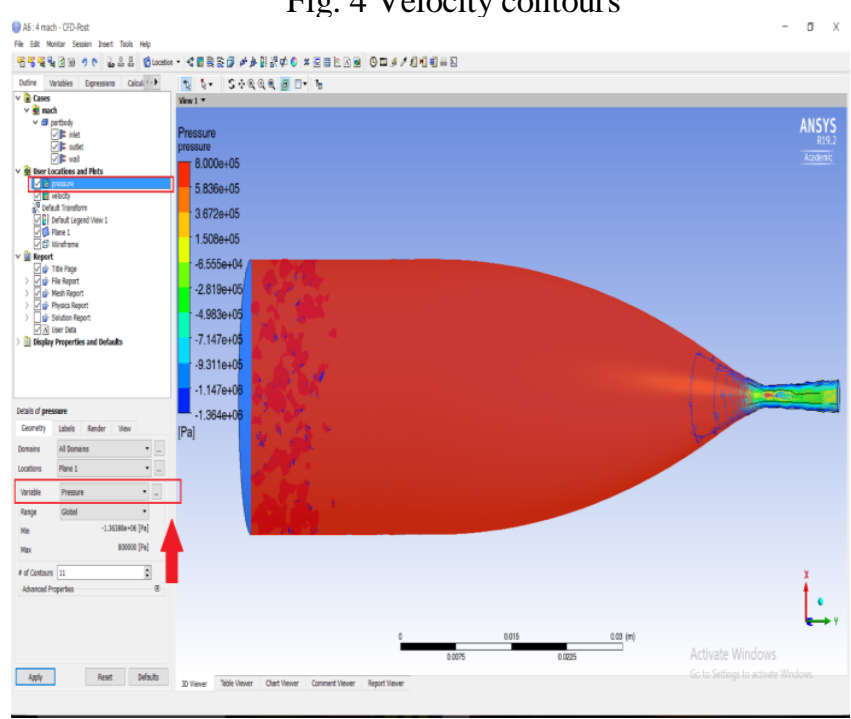

Fig. 5 Pressure contours

\begin{tabular}{|c|c|c|}
\hline \multirow{2}{*}{\multicolumn{2}{|c|}{$\begin{array}{l}\text { Analytical Results } \\
\text { Poutput in Pascal }\end{array}$}} & CFD Results \\
\hline & & Mach number \\
\hline
\end{tabular}

\begin{tabular}{|c|c|c|}
\hline $\mathbf{0 . 4 1 2}$ & $\mathbf{3 2 9 6 0 0}$ & $\mathbf{1 . 4 9}$ \\
\hline $\mathbf{0 . 2 7 2}$ & $\mathbf{2 1 7 6 0 0}$ & $\mathbf{1 . 8 1}$ \\
\hline $\mathbf{0 . 1 2 7}$ & $\mathbf{1 0 1 6 0 0}$ & $\mathbf{1 . 9 0 7}$ \\
\hline $\mathbf{0 . 0 9 3}$ & $\mathbf{7 4 4 0 0}$ & $\mathbf{2 . 0 2}$ \\
\hline $\mathbf{0 . 0 5 8}$ & $\mathbf{4 6 4 0 0}$ & $\mathbf{2 . 5 2}$ \\
\hline $\mathbf{0 . 0 4 2}$ & $\mathbf{3 3 6 0 0}$ & $\mathbf{2 . 6 0}$ \\
\hline $\mathbf{0 . 0 2 7}$ & $\mathbf{2 1 6 0 0}$ & $\mathbf{2 . 9 7}$ \\
\hline $\mathbf{0 . 0 2 0}$ & $\mathbf{1 6 0 0 0}$ & $\mathbf{3 . 0 2}$ \\
\hline $\mathbf{0 . 0 1 3}$ & $\mathbf{1 0 4 0 0}$ & $\mathbf{3 . 4 8}$ \\
\hline $\mathbf{0 . 0 0 6 5}$ & $\mathbf{4 8 0 0}$ & $\mathbf{3 . 8 1}$ \\
\hline
\end{tabular}

Table.3 CFD Obtained Mach numbers

\section{CONCLUSION}

By calculating analytically and solving through ansys fluent software it is found that both values are matching with little deviation but the design of Convergent-Divergent nozzle was able to achieve supersonic speed with taken conditions. And also its recommended to fabricate and test the ConvergentDivergent nozzle with above said dimensions.

\section{ACKNOWLEDGEMENT}

The authors are grateful to the Department of Aeronautical Engineering for its support in R\&D activities and they also thank each and everyone who supported directly or indirectly for this work.

\section{REFERENCE}

[1] George F. Hausmann (February 15, 1956.), Jet Exhaust Nozzle , Glastonbury, Conn., assignor to United Aircraft Corporation, East Hartford, Conn., a corporation of Delaware Application

[2] John Alan Courtney Hyde, (May 11, 1959), Convergent Divergent Nozzle Assembly, assignor to Orenda Engines Limited, Village of Malton, Peel, Ontario, Canada

[3] Joseph, Cincinnati Aerodynamic Nozzle, Ohio, (July 5, 1955), assignor to General Electric Copay, a corporation of New York

[4] Hans P. Mehr, Mason, Ohio (Dec. 8, 1965) ConvergentDivergent Exhaust Nozzle For Supersonic Aircraft, assignor, by mesne assignments, to the United States of America

[5] Thomas F. Tumicki, Yantic, (Sept. 23, 1964) ConvergentDivergent Co-annular Primary Nozzle Conn., assignor to United Aircraft Corporation, East Hartford, Conn., a corporation of Delaware

[6] Norman E. Weeks, Jr., Kansas City, Kans (Feb. 4, 1958) Exhaust Nozzle Having A Flow Area Of Variable Convergency And Overgency, assignor to Westinghouse Electric Corporation, East Pittsburgh, Pa., a corporation of Pennsylvania

[7] Vikash Babu, (2nd edition, 2015.) Fundamentals of Gas Dynamics 
[8] H. Cohen, H.I.H. Saravanamuttoo, G.F.C. Rogers, Paul Straznicky, Andrew Nix(7th Edition)Gas Turbine Theory Gas Turbine Theory

[9] R. Boyanapalli et al. (2013), "Analysis of Composite DeLaval Nozzle Suitable for rocket applications", International Journal of Innovative Technology and Exploring Engineering, 2, pp. 336- 344.

[10] K. Pougatch, M. Salcudean, E. Chan, B. Knapper, (2008), "Modelling of compressible gas-liquid flow in a convergent-divergent nozzle", Chemical Engineering Science, 63, pp. 4176-4188

[11] J.D. Anderson, (1996), "Compressible Flow Through Nozzles" in: "Introduction to Aerodynamics" New York: McGraw-Hill, pp. 510-530.

[12] Q. Xiao, H.M. Tsai, D. Papamoschou, (2007), "Numerical investigation of supersonic flow separation", AIAA Journal, 45, pp. 532-541. 